DOI: 10.12731/2227-930X-2019-1-14-28

УДК 69

\title{
АНАЛИЗ ПРОГРАММНЫХ КОМПЛЕКСОВ И ОПЫТА ВНЕДРЕНИЯ ВІМ-ТЕХНОЛОГИЙ
}

\section{Вербицкий В.A.}

Основной задачей строительных организаций на данный момент является переход на ВIМ-технологии. Информационное моделирование или ВIМ технологии - это интегрированный прочесс, основанный на скоординированной, надежной информации о проекте от проектирования до строительства и эксплуатаџии. В данной статье рассмотрены, сравнение существующих на рынке программных комплексов, а также государственное регулирование применения ВIM-технологий в развитых странах.

Ключевые слова: ВIM; программы; модель; информаџия; технология.

\section{ANALYSIS OF SOFTWARE SYSTEMS AND EXPERIENCE IN IMPLEMENTING BIM-TECHNOLOGIES}

\section{Verbitsky V.A.}

The main task of construction organizations is the transition to BIM-technology. Information modeling or BIM technology is an integrated process based on coordinated, reliable information. This article discusses the comparison of existing software systems on the market, as well as government regulation of the use of BIM-technologies in developed countries.

Keywords: BIM; programs; model; information; technology.

\section{Введение}

Технологии в строительной области не стоят на месте. В области проектирования технологии скакнули от черчения на бумаге до 
3D-моделирования конструкций, но самой вершиной инноваций считается внедрение ВIM-технологий [1].

Увеличение темпов транспортного строительства, все возрастающая конкуренция и мировая практика, стимулируют строительные организации на поиск и использование новых методов проектирования. Именно поэтому сейчас самой обсуждаемой технологией в настоящие время является технология информационного моделирования [2].

$\mathrm{BIM}$, или информационное моделирование здания, представляет собой совместный процесс, управляемый созданием и обменом соответствующей цифровой информацией в течение всего жизненного цикла встроенного актива.

Информационная модель строительства представляет собой цельную систему данных, в которой каждому элементу модели назначены свойства и атрибуты. Строительный объект проектируется как единое целое. Все параметры связаны между собой. Изменение одного параметра повлечет за собой целый ряд изменений остальных параметров, вплоть до чертежей, спецификаций, оценки стоимости, визуализации и календарного графика [3].

BIM-технологии упрощают взаимодействие между участниками строительной компании, позволяют контролировать и устранять ошибки на каждом этапе проектирования [4-6]. В любой момент можно изменить различные параметры объектов и это отразится на всю модель целиком. С помощью ВІМ создание чертежей и отчетов автоматизируется.

В источниках $[7,8]$ приводится много примеров успешного применения ВIM-технологий на реальных объектах. Основные плюсы использования BIM - это сокращение сроков реализации проекта и его стоимости.

Организации при внедрении ВIM сталкиваются с такими проблемами как - сложность перехода, дороговизна, отсутствие достаточного количества специалистов, вероятность монополизации рынка [5, 9]. 
Огромным опытом использования ВIM-технологий обладают зарубежные страны. В статье [10] приводиться успешные овладение и применения ВIM в различных сферах строительства. Вследствие накопленного опыта, в зарубежных источниках [1113] можно найти множество полезной информации для организаций, решивших перейти на информационное моделирование.

На сегодняшний день ВIМ-технологии, в основном, используются для проектирования гражданских объектов [14], однако появилась необходимость внедрения данной технологии и в транспортную инфраструктуру. Сейчас в мире нет ни одного ВIМ-стандарта для комплексного описания линейных объектов [15].

Однако есть небольшое количество проектных организаций в сфере проектирования мостовых сооружений, которые разработали для себя комплексные решения, базирующаяся на технологиях информационного моделирования гражданского строительства [16-20]. В основном мостостроительные компании применяют технологии BIM частично, например, только для оценки фактического состояния мостового сооружения [21].

\section{Материалы и методы исследования}

В основе статьи лежит такой теоретический метод исследования как сравнительный анализ. С помощью него были проанализированы преимущества и недостатки программных комплексов, существующих на рынке, а также проведено сравнение уровня применения и освоения BIM-технологий Российской Федерацией и другими государствами.

\section{Результаты исследования}

На сегодняшний день существует множество программных комплексов от различных компаний, предлагающих свои индивидуальные решения по технологии информационного моделирования. Многие из этих комплексов поддерживают отдельные элементы информационного моделирования и обладают широкими возможностями. 


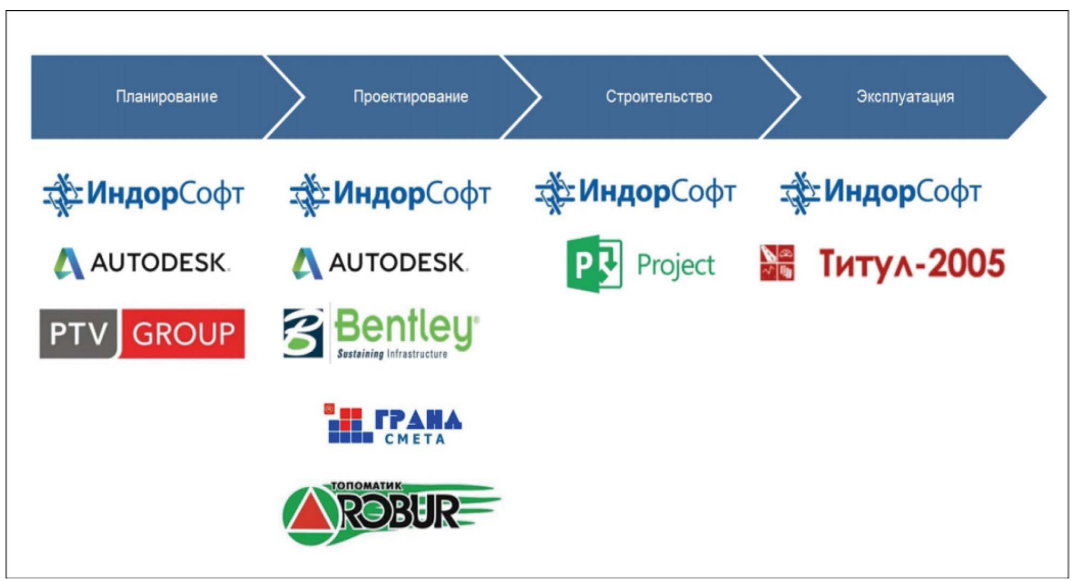

Рис. 1.1. Технологическая цепочка - (Источник:https://cyberleninka.ru/article/v/ informatsionnoe-modelirovanie-pri-razrabotke-proektnoy-dokumentatsii)

Основными поставщиками программных продуктов на российском рынке являются компании Bentley и Autodesk. Они имеют в своем арсенале программы для проектирования мостовых сооружений. Используя взаимодействие продуктов компании Autodesk, можно создать информационную модель на стадии ТЭО в Infraworks [23], передать её на следующий этап, используя программу Civil 3D и Revit, запроектировать мостовое сооружения и далее перебросить в Navisworks [24] на экспертизу проекта и связи модели с календарно-сетевым планированием для управления процесса строительства. В качестве базы для общих данных используется Autodesk Valut [25].

Также на рынке существуют программные комплексы отечественных производителей, такие как ООО «Топоматик» [26], ООО «ИндорСофт» [27], ООО «Кредо-Диалог» [28], которые не уступают признанным лидерам, а в чем-то даже превосходят их. Главным преимуществом отечественных программных комплексов это соотношение «цена/качество» и то, что их основа лежит на нормах и стандартах, которые могут существенно отличаться от зарубежных. 


\section{Сравнение возможностей отечественных продуктов \\ Таблица 1.1. \\ и продукции конкурентов Autodesk и Bentley в разрезе жизненного цикла и отдельных технологических процессов:}

\begin{tabular}{|c|c|c|c|}
\hline $\begin{array}{l}\text { СТАДИИ ЖИЗНЕННОГО ЦИКЛА } \\
\text { И ТЕХНОЛОГИЧЕСКИЕ ПРОЦЕССЫ }\end{array}$ & ОТЕЧЕСТВЕННЫЕ ТЕХНОЛОГИИ & AUTODESK & BENTLEY \\
\hline 1. Концептуальное проектирование & IndorGIS & Infraworks & - \\
\hline 2. Планировка территории & CREDO ГЕНПЛАН, IndorCAD/Site & Civil 3D & Power Civil \\
\hline $\begin{array}{l}\text { 3. Инженерные изыскания } \\
\text { (геология и геодезия) }\end{array}$ & $\begin{array}{l}\text { CREDO_DAT, CREDО ГЕОЛОГИЯ, } \\
\text { IndorSurvey, IndorCloud }\end{array}$ & $\begin{array}{l}\text { Geotechnical module } \\
\text { (геология) }\end{array}$ & $\begin{array}{l}\text { PowerSurvey, gINT, } \\
\text { GeoStructural Analysis }\end{array}$ \\
\hline $\begin{array}{l}\text { 4. Геометрическое проектирование } \\
\text { (стадии «Пџ и «Р») }\end{array}$ & $\begin{array}{l}\text { IndorCAD/Road, CREDO Автомобильные } \\
\text { дороги, Robur - Автомобильные дороги }\end{array}$ & Civil 3D & $\begin{array}{l}\text { OpenRoads, InRoads, } \\
\text { MXRoad, Power Civil, GEOPAK }\end{array}$ \\
\hline $\begin{array}{l}\text { 5. Проектирование (дорожные } \\
\text { одежды, поС, ППР, сметы) }\end{array}$ & $\begin{array}{l}\text { IndorPavement, CREDO РAДОН, Robur - } \\
\text { Дорожные одежды, IndorCAD/Road, } \\
\text { Гранд-Смета, АВС, Госстройсмета }\end{array}$ & - & - \\
\hline 6. Подготовка чертежей & IndorDraw, nanoCAD & AutoCAD & Microstation \\
\hline 7. Эксплуатация (ГИС) & IndorRoad, Титул-2005 & - & - \\
\hline 8. Реализация проектов & IndorRoad & Navisworks & ProjectWise with ConstructSim \\
\hline $\begin{array}{l}\text { 9. Проектирование организачии } \\
\text { дорожного движения }\end{array}$ & $\begin{array}{l}\text { CREDO Дислокация, Титул-2005, } \\
\text { Road Office, IndorRoad }\end{array}$ & - & - \\
\hline 10. Паспортизация и диагностика & IndorRoad, Титул-2005, СВПД & - & - \\
\hline 11. Проектирование мостов & ЛИРА, SCAD, АИС ИСО & Revit & RM Bridge \\
\hline 12. Эксплуатация мостов & АИС ИСО & - & AssetWise \\
\hline 13. Проектирование типовых тру6 & $\begin{array}{l}\text { IndorCulvert, Robur - Искусственные } \\
\text { сооружения, CREDO Трубы, ЛИРА, SCAD }\end{array}$ & - & - \\
\hline 14. Эксплууатация тру6 & IndorRoad & - & - \\
\hline
\end{tabular}

(Источник:http://www.cadgis.ru/2015/5/CADGIS-2015-2(5).pdf)

Таблийа 1.2.

\section{Сравнение возможностей отечественных продуктов и продукции конкурентов Autodesk и Bentley в разрезе ВIМ-элементов:}

\begin{tabular}{|c|c|c|c|}
\hline ЭЛЕМЕНТЫ ИМД & ОТЕЧЕСТВЕННЫЕ ТЕХНОЛОГИИ & AUTODESK & BENTLEY \\
\hline 1. Среда общих данных & $\begin{array}{c}\text { CREDO Автомобильные дороги } \\
\text { (при проектировании), IndorRoad } \\
\text { (при эксплуатации) }\end{array}$ & Revit & ProjectWise \\
\hline $\begin{array}{l}\text { 2. Совместный просмотр } \\
\text { и рецензирование }\end{array}$ & CREDO (при проектировании) & A360, DesignReview & ProjectWise \\
\hline 3. Организация жизненного цикла & IndorCAD + IndorRoad & - & $\begin{array}{l}\text { ProjectWise + } \\
\text { AssetWise }\end{array}$ \\
\hline 4. Уровни проработки моделей & - & - & - \\
\hline 5.Управление проектами & - & Revit & ProjectWise \\
\hline $\begin{array}{l}\text { 6. Параметризированные модели } \\
\text { данных }\end{array}$ & IndorCAD, CREDO, Robur & Civil 3D & $\begin{array}{l}\text { OpenRoads, InRoads, } \\
\text { MXRoad, Power Civil, GEOPAK, } \\
\text { RM Bridge }\end{array}$ \\
\hline $\begin{array}{l}\text { 7. Открытые форматы обмена } \\
\text { данными }\end{array}$ & + & + & + \\
\hline $\begin{array}{l}\text { 8. Библиотеки объектов } \\
\text { и материалов }\end{array}$ & $\begin{array}{l}\text { IndorCAD, IndorPavement, IndorCulvert, } \\
\text { CREDO }\end{array}$ & Revit & RM Bridge \\
\hline 9. 4D - План реализации проекта & IndorCAD/Road, IndorRoad & NavisWorks & ProjectWise with ConstructSim \\
\hline 10. 5D - Ведомости и сметы & $\begin{array}{l}\text { IndorCAD/Road, CREDO Автомобильные } \\
\text { дороги, Robur - Автомобильные дороги }\end{array}$ & Civil 3D & $\begin{array}{l}\text { OpenRoads, InRoads, } \\
\text { MXRoad, Power Civil, GEOPAK, } \\
\text { RM Bridge }\end{array}$ \\
\hline $\begin{array}{l}\text { 11. 6D - Оценка проектных } \\
\text { решений }\end{array}$ & $\begin{array}{l}\text { IndorCAD/Road, CREDO Автомобильные } \\
\text { дороги, Robur - Автомобильные дороги }\end{array}$ & Civil 3D, Revit & $\begin{array}{l}\text { OpenRoads, InRoads, } \\
\text { MXRoad, Power Civil, GEOPAK, } \\
\text { RM Bridge }\end{array}$ \\
\hline 12. 7D - Эксплуатация & IndorRoad & - & AssetWise \\
\hline
\end{tabular}

(Источник:http://www.cadgis.ru/2015/5/CADGIS-2015-2(5).pdf) 
Также сейчас на рынке пользуются популярностью такие продукты как - SOFiSTiK, Midas, Allplan Bridge. C помощью данных программных комплексов было возведено большое количество уникальных мостовых сооружений.

5 февраля 2014 года состоялось заседание Консультативного совета по безопасному и рациональному недропользованию в ТЭК при председателе Комитета Госдумы РФ по энергетике на тему «Разработка национального плана мероприятий по внедрению инновационных технологий информационного цикла объектов капитального строительства: инвестиции, проектирование, строительство и безопасная эксплуатация».

4 марта 2014 года премьер-министр Д.А. Медведев провел заседание президиума Совета при Президенте Российской Федерации по инновационному развитию России в сфере строительства, и по модернизации экономики, на котором обсуждался вопрос внедрения информационного моделирования в сфере гражданского и промышленного строительства. По итогам данного заседания было издано поручение по внедрению информационного моделирования.

29 декабря 2014 года глава Минстроя Мень М.А. подписал приказ «Об утверждении плана поэтапного внедрения технологий информационного моделирования в области гражданского и промышленного строительства.

23 ноября 2018 года замминистра строительства Дмитрий Волков анонсировал создание при Минстрое открытой экспертной группы по внедрению технологий информационного моделирования на всех этапах объектов капитального строительства.

7 декабря 2018 года на форуме 100+ Forum Russia Владимир Якушев сообщил о разработанных Минстроем стандартах, способствующих эффективному внедрению информационного моделирования в строительную отрасль России.

По заказу Государственной компании «Автодор» выполняются научно-исследовательская работа на тему «Разработка рекомендаций по использованию инновационных технологий информацион- 
ного моделирования на всех этапах жизненного цикла автомобильных дорог» [29]. В результате данной работы появятся:

- «организационная и технологическая поддержка формирования информационной модели автомобильной дороги на всех этапах жизненного цикла»;

- рекомендации по созданию информационных моделей;

- рекомендации по поддержанию и развитию информационных моделей;

- рекомендации по использованию и созданию технологий моделирования на всех стадиях жизненного цикла автомобильных дорог.

На данный момент во многих странах мира, например, - Франция, страны Северной Европы, Сингапур США, Великобритания, Южная Корея, Китай и др., активно внедряются ВІМ-технологии.

BIM-технологии в результате принесло высокое качество проектируемой документации, снижение затрат на этапе строительства, хранение информации в едином месте и упрощение взаимодействия участников, входящих в состав строительных проектов, налаживание информационного обмена. Все это приводит к повышению экономической эффективности от реализации проекта строительства зданий и сооружений. Причем такой положительный эффект повышения уровня рентабельности проявляется как на государственном уровне, так и на уровне отдельно взятой организации.

В ряде стран принято на государственном уровне обязательное использование BIM-технологий при проектировании и строительстве объектов за счет государственного бюджета. Такие требования оглашались государственными заказчиками в США начиная с 2003 года, а в ряде стран Европы и Азии - с 2007 года. Великобритания в 2011 году объявила о новой программе в области строительства, ориентированной на достижения конкурентных преимуществ на мировой арене.

США в 2012 году около 70\% участников рынка строительства объявили о применении в своих проектах ВІМ-технологии, в Великобритании в 2016 году $-54 \%$. 
Сингапур сейчас является одним из лидеров по применению ВIM-технологий во всем мире. С 2015 года более $80 \%$ всех строительных проектов выполняются с применением BIM-технологий. Правительство Сингапура сразу выявили преимущества информационной технологии и поэтому развернули государственную политику по поддержке ее внедрения.

\section{Обсуждение}

Развитие технологий проектирований развивается постоянно, находят все новые применения новым программным комплексам, которые в свою очередь получают серьезные обновления. Все это способствует снижению трудозатрат на выполнения конкретного проекта и ошибок при проектировании, а также к увеличению эффективности труда.

Главным достоинством ВІМ моделей является ее динамичность, то есть, если изменить отдельный элемент модели, за этим следует целая цепочка пересчета и обновления данных, параметров связанных документов.

Сравнение программных комплексов различных производителей показало, что нет единого программного комплекса для решения всех видов задач. Даже различные программы отдельного производителя не могу полностью покрыть все стадии жизненного цикла объекта.

Так же в ходе исследования выяснилось, что ВІМ-технологии в Российских строительных организациях только на стадии внедрения, а в развитых странах уже активно используют данную технологию для реализации проектов любой сложности.

В дальнейшем необходимо провести исследование значительных недостатков и сложности внедрения ВIМ-технологий в Российской Федерации.

\section{Заключение}

Можно с уверенностью сказать, что за данной технологией будущие. Информационное моделирование позволяет при стро- 
ительстве существенно экономить денежные средства и время специалистов, так как дает возможность проанализировать и заранее протестировать работоспособность всех инженерных решений и концепций еще до начала процесса строительства.

На данный момент существуют множество программ для решения задач при создании ВIM модели, но им необходимы доработки.

Опыт российских компаний, внедривших ВIM-технологию показал, что она позволяет снизить стоимость строительства до $30 \%$, сократить сроки проектирования на 30\%, на 5-10\% уменьшить стоимость эксплуатации объекта [22]. Уже сегодня можно увидеть BIM-технологию в тендерной документации.

\section{Список литературы}

1. Морина Е.А., Макаров А.И. ВІМ-технологии в мостовом проектировании // Строительство уникальных зданий и сооружений. 2017, №6. С. 30-46.

2. Лигоцкий А.Н. Информационное моделирование при разработке проектной документации // САПР и ГИС автомобильных дорог. 2016, №1. С. 12-18.

3. Воронин И.А Изатов В.А. Методические и организационные аспекты сопряжения САПР со сметноэкономическими системами // САПР и ГИС автомобильные дороги. 2014, №1. С. 57-60.

4. Биктимиров К. Что такое ВIM, и с чем его едят [Электронный pecypc]. URL: https://kilonewton.ru/blog/21 (дата обращения: 10.09.2016).

5. Autodesk. Что такое ВIM-технологии (Building Information Modeling) в современной интерпретации. [Электронный ресурc]. URL: http:// www.autodesk.ru/campaigns/aec-building-design-bds-newseats/ landing-page (дата обращения: 08.04.2019).

6. Autodesk. Информационное моделирование объектов промышленного и гражданского строительства. URL: http://damassets.autodesk. net/content/dam/autodesk/www/campaigns/metro/img/bim_brochure. pdf (дата обращения: 08.04.2019). 
7. Батишев В. Из практики информационного моделирования // SportBuild. 2015. № 6/7. C. 22-27.

8. Талапов В. Технология ВIM: расходы на внедрение и доходы от использования. [Электронный ресурc]. URL: http://isicad.ru/ru/ articles.php?article_num=16748 (дата обращения: 02.04.2019).

9. Lushnikov A.S. Problems and advantages of implementing BIM-technologies in construction companies. Herald of Civil Engineers. [Проблемы и преимущества внедрения ВІМ-технологий в строительных компаниях. Вестник гражданских инженеров]. 2015. No. 6(53), pp. 252-256. (rus)

10. Ho S., Rajabifard A. Towards 3D-enabled urban land administration: Strategic lessons from the BIM initiative in Singapore. Land Use Policy. [На пути к управлению городскими землями с поддержкой 3D: стратегические уроки из инициативы BIM в Сингапуре. Политика землепользования]. 2016. o. 57, pp. 1-10.

11. Mumovica D., Greeningb P., Eleftheriadisa S. Life cycle energy efficiency in building structures: A review of current developments and future outlooks based on BIM capabilities. Renewable and Sustainable Energy Reviews. [Энергоэффективность жизненного цикла в строительных конструкциях: обзор текущих событий и перспектив на основе возможностей ВIM. Обзоры возобновляемых и устойчивых источников энергии]. 2017. №. 67, pp. 811-825.

12. Natha T., Tionga R., Attarzadeha M., Yuc Z., Chidambaramb C. Productivity improvement of precast shop drawings generation through BIM-based process re-engineering. Automation in Construction. [Повышение производительности при создании сборных чертежей сборного цеха путем реинжиниринга процессов на основе BIM. Автоматизация в строительстве]. 2015. o. 54, pp. 54-68.

13. Filin S., Zeibak-Shini R., Ma L., Sacks R. Towards generation of as-damaged BIM models using laser scanning and as-built BIM: First estimate of as-damaged locations of reinforced concrete frame members in masonry infill structures. Advanced Engineering Informatics. [На пути к созданию моделей ВIM в поврежденном состоянии с использованием лазерного сканирования и встроенного ВIM: 
первая оценка поврежденных местоположений железобетонных элементов каркаса в каменной кладке заполнить структуры. Инженерная Информатика]. 2016. №. 30, pp. 312-326.

14. Skvortsov A.V. Standards for data exchange. Car roads. [Стандарты для обмена данными. Автомобильные дороги]. 2015. No. 2, pp. 84-89. (rus)

15. Skvortsov A.V. BIM Highways: Assessing the Maturity of Technology. SAP CAD and GIS for roads. [BIM Автострада: Оценка зрелостью технологии. SAP CAD и ГИС для дорог]. 2014. No. 2(3), pp. 12-21. (rus)

16.Завтур А., Гришина Н. Автоматизация дорожного строительства. Опыт компании КРОК в ВІМ технологиях // Строительные материалы, оборудование, технологии ХХІ века. 2016. № 5-6. С. 26-29.

17. Скворцов А.В. ВІМ для дорожной отрасли: что-то новое или мы этим уже занимаемся? // САПР и ГИС автомобильных дорог. 2014. № 1(2). C. 8-11.

18. Субботин С.А., Петренко Д.А. ВІМ-решения «Индорсофт» для проектирования и эксплуатации автомобильных дорог // САПР и ГИС автомобильных дорог. 2015. № 2(5). С. 100-107.

19. Скворцов А.В. ВІМ автомобильных дорог: оценка зрелости технологии // САПР и ГИС автомобильных дорог. 2014. № 2(3). С. 12-21.

20. Морозова А.С. Инновации в дорожном проектировании // Путь и путевое хозяйство. 2014. № 11. С. 37-40.

21.Ботяновский А.А., Пастушков В.Г. Применение ВІМ-технологий и новейшего оборудования при исследовании фактического технического состояния мостового сооружения // Модернизация и научные исследования в транспортном комплексе. 2015. № 1. C. 342-345.

22. Талапов В.В. Основы ВІМ: введение в информационное моделирование зданий. М.: ДМК Пресс, 2011. 392 с.

23. [Электронный ресурс]. URL: https://www.autodesk.com/products/ infraworks/overview (дата обращения: 01.04.2019).

24. [Электронный ресурc]. URL: https://www.autodesk.ru/products/ navisworks/overview (дата обращения: 03.04.2019). 
25. [Электронный ресурс]. URL: https://www.autodesk.com/products/ vault/overview (дата обращения: 03.04.2019).

26. [Электронный ресурc]. URL: http://www.topomatic.ru/ (дата обращения: 04.04.2019).

27. [Электронный ресурc]. URL:https://www.indorsoft.ru/ (дата обращения: 05.04.2019).

28. [Электронный ресурс]. URL:https://credo-dialogue.ru/ (дата обращения: 09.04.2019).

29. [Электронный pecypc]. URL:http://www.bim-proekt.ru/events/ presentation/rekomendacii-po-ispolzovaniy-tim.pdf (дата обращения: 08.04.2019).

\section{References}

1. Morina E.A., Makarov A.I. BIM-texnologii v mostovom proektirovanii [BIM-technologies in bridge design]. Stroitel'stvo unikal'nyx zdanij $i$ sooruzhenij [Construction of unique buildings and structures]. 2017, №6, pp. 30-46.

2. Ligockij A.N. Informacionnoe modelirovanie pri razrabotke proektnoj dokumentacii [Information modeling in the development of project documentation]. SAPR $i$ GIS avtomobil'nyx dorog [CAD and GIS roads]. 2016, №1, pp. 12-18.

3. Voronin I.A Izatov V.A. Metodicheskie i organizacionnye aspekty sopryazheniya SAPR so smetnoekonomicheskimi sistemami [Methodical and organizational aspects of CAD interfacing with estimated economic systems]. SAPR $i$ GIS avtomobil'nye dorogi [CAD and GIS roads]. 2014, №1, pp. 57-60.

4. Biktimirov K. CHto takoe BIM, is chem ego edyat [BIM, and with what it is eaten]. https://kilonewton.ru/blog/21

5. Autodesk. CHto takoe BIM-texnologii (Building Information Modeling) $v$ sovremennoj interpretacii [What is BIM-technology in modern interpretation]. http://www.autodesk.ru/campaigns/aec-building-designbds-newseats/landing-page

6. Autodesk. Informacionnoe modelirovanie ob"ektov promyshlennogo i grazhdanskogo stroitel'stva [Information modeling of industrial and 
local construction.]. http://damassets.autodesk.net/content/dam/autodesk/www/campaigns/metro/img/bim_brochure.pdf

7. Batishev V. Iz praktiki informacionnogo modelirovaniya [From the practice of information modeling]. SportBuild. 2015. № 6/7, pp. 22-27.

8. Talapov V. Texnologiya BIM: rasxody na vnedrenie $i$ doxody ot ispol'zovaniya [BIM technology: costs of implementation and receipt from use]. URL: http://isicad.ru/ru/articles.php?article_num=16748

9. Lushnikov A.S. Problems and advantages of implementing BIM-technologies in construction companies. Herald of Civil Engineers. 2015. No. 6(53), pp. 252-256.

10. Ho S., Rajabifard A. Towards 3D-enabled urban land administration: Strategic lessons from the BIM initiative in Singapore. Land Use Policy. 2016. No. 57, pp. 1-10.

11. Mumovica D., Greeningb P., Eleftheriadisa S. Life cycle energy efficiency in building structures: A review of current developments and future outlooks based on BIM capabilities. Renewable and Sustainable Energy Reviews. 2017. No. 67, pp. 811-825.

12. Natha T., Tionga R., Attarzadeha M., Yuc Z., Chidambaramb C. Productivity improvement of precast shop drawings generation through BIM-based process re-engineering. Automation in Construction. 2015. No. 54, pp. 54-68.

13. Filin S., Zeibak-Shini R., Ma L., Sacks R. Towards generation of as-damaged BIM models using laser scanning and as-built BIM: First estimate of as-damaged locations of reinforced concrete frame members in masonry infill structures. Advanced Engineering Informatics. 2016. No. 30, pp. 312-326.

14. Skvortsov A.V. Standards for data exchange. Car roads. 2015. No. 2, pp. 84-89. (rus)

15. Skvortsov A.V. BIM Highways: Assessing the Maturity of Technology. SAP CAD and GIS for roads. 2014. No. 2(3), pp. 12-21.

16.Zavtur A., Grishina N. Avtomatizaciya dorozhnogo stroitel'stva. Opyt kompanii KROK v BIM texnologiyax [Automation of road construction. CROC's experience in BIM technologies]. Stroitel'nye materialy, 
oborudovanie, texnologii XXI veka [Building materials, equipment, technologies of the XXI century]. 2016. № 5-6, pp. 26-29.

17. Skvorcov A.V. BIM dlya dorozhnoj otrasli: chto-to novoe ili my etim uzhe zanimaemsya? [BIM for the road industry: are we already engaged?]. SAPR i GIS avtomobil'nyx dorog [CAD and GIS roads]. 2014. № 1(2), pp. 8-11.

18. Subbotin S.A., Petrenko D.A. BIM-resheniya «Indorsoft» dlya proektirovaniya i ekspluatacii avtomobil'nyx dorog [BIM-solutions "Indorsoft" for the design and operation of roads]. SAPR $i$ GIS avtomobil'nyx dorog [CAD and GIS roads]. 2015. № 2(5), pp. 100-107.

19. Skvorcov A.V. BIM avtomobil'nyx dorog: ocenka zrelosti texnologii [BIM highways: assessment of technology maturity]. SAPR i GIS avtomobil'nyx dorog [CAD and GIS highways]. 2014. № 2(3), pp. 12-21.

20. Morozova A.S. Innovacii v dorozhnom proektirovanii [Innovations in the road project]. Put'i putevoe xozyajstvo [Path and track facilities]. 2014. № 11, pp. 37-40.

21. Botyanovskij A.A., Pastushkov V.G. Primenenie BIM-texnologij i novejshego oborudovaniya pri issledovanii fakticheskogo texnicheskogo sostoyaniya mostovogo sooruzheniya [The use of BIM technologies and the latest equipment in the study of the actual technical condition of the bridge structure]. Modernizaciya i nauchnye issledovaniya $v$ transportnom komplekse [Modernization and research in the transport complex]. 2015. № 1, pp. 342-345.

22. Talapov V.V. Osnovy BIM: vvedenie v informacionnoe modelirovanie zdanij [BIM Basics: An Introduction to Building Information Modeling]. M.: DMK Press, 2011. 392 p.

23.https://www.autodesk.com/products/infraworks/overview

24.https://www.autodesk.ru/products/navisworks/overview

25.https://www.autodesk.com/products/vault/overview

26.http://www.topomatic.ru/

27.https://www.indorsoft.ru/

28.https://credo-dialogue.ru/

29. http://www.bim-proekt.ru/events/presentation/rekomendacii-po-ispolzovaniy-tim.pdf 


\section{ДАННЫЕ ОБ АВТОРЕ}

Вербицкий Владислав Андреевич, студент 2 курса магистратуры

Тюменский индустриальный университет

ул. Володарского, 38, г. Тюмень, 625000, Российская Федеращчия

verrbick@mail.ru

\section{DATA ABOUT THE AUTHOR}

Verbitsky Vladislav Andreevich, 2nd year student of the master's program

Industrial University of Tyumen

38, Volodarsky Str., Tyumen, 625000, Russian Federation

verrbick@mail.ru

ORCID: 0000-0001-7540-7831 